\title{
Successful Stent-Retriever Thrombectomy for Acute Cerebral Embolization After Transcatheter Aortic Valve Implantation
}

Mizuki Miura, MD; Shinichi Shirai, MD; Katsumi Inoue, MD;

Masaomi Hayashi, MD; Shinichi Kakumoto, MD; Katsuhiro Seo, MD;

Yoshio Arai, MD; Michiya Hanyu, MD; Kenji Ando, MD

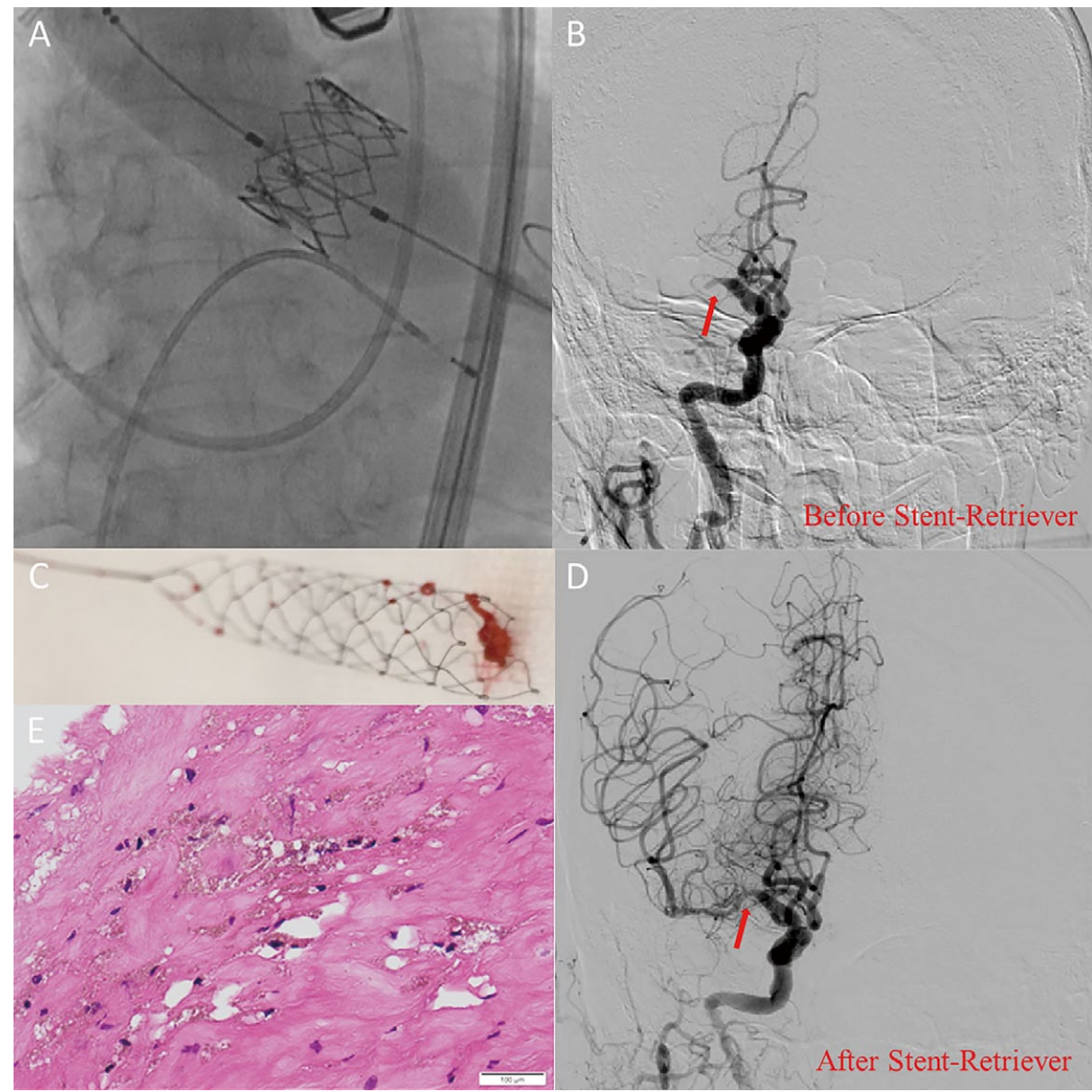

Figure. (A) A 26-mm SAPIEN XT deployed via a transfemoral approach. (B) Cerebral angiography showing the occluded right middle cerebral artery (MCA). (C) Embolic tissue retrieved from the right MCA. (D) Cerebral angiography showing recanalization of the right MCA. (E) On pathology, the obstructing material was intimal fibrous plaque derived from the aortic wall.

Received November 24, 2016; accepted November 27, 2016; released online December 16, 2016 Time for primary review: 3 days Department of Cardiology (M.M., S.S., M. Hayashi, K.A.), Department of Laboratory Medicine (K.I.), Department of Anesthesiology (S.K., K.S.), Department of Cardiovascular Surgery (Y.A., M. Hanyu), Kokura Memorial Hospital, Kitakyushu, Japan

Mailing address: Shinichi Shirai, MD, Department of Cardiology, Kokura Memorial Hospital, 3-2-1 Asano, Kokurakita-ku, Kitakyushu 802-8555, Japan. E-mail: shirai440130@gmail.com

ISSN-1346-9843 All rights are reserved to the Japanese Circulation Society. For permissions, please e-mail: cj@j-circ.or.jp 
A n 82-year-old man with symptomatic severe aortic stenosis underwent transcatheter aortic valve implantation (TAVI) using a 26-mm balloon-expandable SAPIEN XT (Edwards Lifesciences, Irvine, CA, USA). It was deployed via a transfemoral approach under general anesthesia (Figure A). After extubation, a disturbance of consciousness and paralysis of the left side of the body were detected. We immediately performed magnetic resonance imaging (MRI), which showed occlusion of the right middle cerebral artery (MCA). We consulted the neuro-intervention team, and they decided to perform cerebral angiography, which showed that the right MCA was occluded at the M1 portion (red arrow, Figure B; Movie S1); therefore the neurovascular team inserted a stent-retriever system (SOLITAIRETM $^{T} 26 \times 30 \mathrm{~mm}$, Covidien; Irvine, CA, USA), and a piece of tissue was recovered from the stent (Figure C). We recanalized the right MCA (red arrow, Figure D; Movie S2), and the estimated total ischemic time was within $2 \mathrm{~h}$. On pathology, the obstructing material was intimal fibrous plaque derived from aortic wall (Figure E). After intervention, the paralysis dramatically improved. The patient was discharged from hospital on foot.

The incidence of peri-procedural stroke in TAVI has gradually decreased with the introduction of new TAVI devices but, once stroke occurs, the clinical course is usually poor. Two case reports have documented successful interventions for an embolized fragment after TAVI. In one case, it may have detached from the native valve or the aortic wall. ${ }^{1}$ In the other case, it detached from the native aortic valve. ${ }^{2}$ To our knowledge, this is the first report on successful stent-retriever thrombectomy for acute stroke caused specifically by aortic plaque embolization after TAVI. Cooperation with the stroke care team and early invasive approach for unexpected embolization enable minimization of damage, as does the use of a filter device during the procedure to prevent further embolization.

\section{References}

1. Fassa AA, Mazighi M, Himbert D, Deschamps L, Ducrocq G, Cheong AP, et al. Successful endovascular stroke rescue with retrieval of an embolized calcium fragment after transcatheter aortic valve replacement. Circ Cardiovasc Interv 2014; 7: 125126.

2. Anuwatworn A, Raizada A, Kelly S, Stys T, Jonsson O, Stys A. Stroke with valve tissue embolization during transcatheter aortic valve replacement treated with endovascular intervention. JACC Cardiovasc Interv 2015; 8: 1261-1263.

\section{Supplementary Files}

Supplementary File 1

Movie S1. Cerebral angiography showing the occluded right middle cerebral artery.

Supplementary File 2

Movie S2. Cerebral angiography showing recanalization of the right middle cerebral artery.

Please find supplementary file(s);

http://dx.doi.org/10.1253/circj.CJ-16-1192 